\title{
VITAMIN D SEASONAL VARIATION OF ELDERLY PEOPLE IN KONYA RESIDANTAL CARE
}

Ahmet Kaya, Elif Turan

Necmettin Erbakan University, Meram Faculty of Medicine Department of

Endocrinology and Metabolism, Konya, Turkey

INTRODUCTION: Vitamin D insufficiency has been shown to be very common in the elderly people, especially in residents of nursing home, in the housebound and in geriatric patients. The synthesis of vitamin D3 (VD3) in the skin under influence of UV light decreases with aging due to insufficient sunlight exposure and decreased functional capacity of the skin. The diet contains a minor part of vitamin $D(V D)$ requirement. In Turkey, Where dairy products are not fortified with VD, VD intake is usually low and the its status mainly depends on sunlight exposure. The most common factors associated with inadequate VD levels included limited sun exposure, lack of dietary VD intake, nursing home environment, wintertime and increasing age.

Many factors influence intensity and duration of exposure to ultraviolet, including geographic location, season, dietary intake, atmospheric conditions and the daily length of time spent outdoors. Hypovitaminosis $D$ and low calcium intake cause increased secretion of parathyroid hormone, leading to bone loss, high bone turnover, mineralization defects, myopathy, falls, hip and other fractures (1). The insidence of falls is high in older women and men. VD supplementation causes a decrease of serum parathyroid (PTH) concentration, a decrease of bone turnover and an increase of bone mineral density. VD3 is recommended in housebound elderly and it may be cost effective in hip fracture prevention in selected risk groups. Hypovitaminosis D can be defined as serum 25-hydroxyvitamin D (25OHD), at which serum PTH concentration starts to increase, with a cut of level of $50 \mathrm{nmol} / \mathrm{L}(=20 \mathrm{ng} / \mathrm{mL})$ or less for serum $250 \mathrm{HD}(2)$. In this study was performed to determine the prevelance of hypovitaminosis in elderly, in Konya Residental Care (RC).

METHOD: 41 people(22 men, 19 women) living in Konya RC were taken study. Serum VD3 measured.These parametres were compared with wintersummer VD3 levels. Results were evaluated firstly between each other and then with 20 elder persons (10 women, 10 men) who had the similar demographic conditions, healty and live outside the RC. Venous blood samples were taken between January and February in winter, June and August in summer. In all subjects blood samples was drawn for mesurement of 250HD. After centrifugation at $2000 \mathrm{~g}$ for $10 \mathrm{~min}$ at room temperature, 3 and $5 \mathrm{ml}$ serum samples were sent on same day to the laboratory to be frozen at $-70{ }^{\circ} \mathrm{C}$ and stored before analysis. Serum 25OHD measured by high performance liquid chromatography (HPLC). The range is normal adult in winter $10-60 \mathrm{ng} / \mathrm{mL}$, in summer 20-120 ng/mL. Exclusion criteria was parathyroid, thyroid, hepatic or renal disease or taking drugs known to influence bone metabolism, such as VD, calcium, corticosteroids and hormone replacement therapy with a bisphosphonate and calcitonine. Statistical analysis was performed using the programme SPSS for Windows. Differences between both patient groups were analysed using Mann-Whitney $U$ tests. Paired simple test is comparing winter and summer VD3 levels. The results were found as $(p<0.05)$ statistically significant.

RESULTS: RC people mean age was $74.75 \pm 3,90$ (65-93), in control groups (CG) were $74,75 \pm 3,90$ (68-83). Mean VD3 level was $20,36 \pm 6,54 \mathrm{ng} / \mathrm{ml}$ in summer, and $19,29 \pm 6,00 \mathrm{ng} / \mathrm{ml}$ in winter for men, Mean VD3 level was $19,58 \pm 6,93 \mathrm{ng} / \mathrm{ml}$ in summer, and $18,29 \pm 4,69 \mathrm{ng} / \mathrm{ml}$ in winter for women in RC group. Mean VD3 level was $24.79 \pm 6,59 \mathrm{ng} / \mathrm{ml}$ in summer, and $20,94 \pm 5,29 \mathrm{ng} / \mathrm{ml}$ in winter for men, For women the avarage value was $25.30 \pm 6,77 \mathrm{ng} / \mathrm{ml}$ in summer $-20,73 \pm 6,50 \mathrm{ng} / \mathrm{ml}$ in winter in control group. There was no difference in mean values between RC people and CG, in the summer and winter period.
In RC men mean VD levels, there was no difference between CG men in summer $(p=0,119)$ and in winter $(p=0,269)$. In $R C$ women mean VD levels there was significant difference $(p=0,008)$ in summer to control women, in winter there was no difference $(p=0,146)$. Physical activity (PA) evaluated in RC people as enough or not, in winter and in summer there was no significant difference between on sufficient PA acording to insufficient PA (winter $p=0,237$, summer $p=0,173)$. The avarage VD intake were found as $400 \mathrm{IU} /$ weekly and calcium intake were $781 \mathrm{mg} /$ day. They were much lower than the recommended When grouped according to length of stay in RC, between 1-4 years total of 29 people in 16 (\%55.17) VD3 level <20 $\mathrm{ng} / \mathrm{mL}$, in 13 people (\%44.82) VD $>20 \mathrm{ng} / \mathrm{mL}, 5$ years and over total of 12 people in 6 (\%50) VD level $>20 \mathrm{ng} / \mathrm{ml}$ was detected in summer. In winter between 1-4 years total of 29 people in 19 (\%65.51) VD level $<20 \mathrm{ng} / \mathrm{mL}$ in 10 people (\%34.4) VD >20 ng/mLwas found. 5 years and over total of 12 people in 9 (\%75) VD $<20 \mathrm{ng} / \mathrm{mL}$, in 3 (\%25) people $>20$ was found. When staying time in $\mathrm{RC}$ is increased, the number of persons is raised with VD deficiency.

DISCUSSION: VD is not required only for bone development and growth of children, it is also required bone strength in adults and prevent osteoporosis and fracture risk in the elderly. All over the world VD deficiency appears to be common in sick and elderly populations (3). Dawson et al 25OHD levels below $25 \mathrm{nmol} / \mathrm{L}$ was found $\% 21$ of elder people, Harris et al 25OHD levels below $50 \mathrm{nmol} / \mathrm{L}$ was found $\% 35$ of elder people, LeBoff et al, VD deficiency has been identified in $50 \%$ of patients with hip fracture vitamin $D$ deficiency has been identified (4).

Inadequate sunlight is a major risk factor for hypovitaminosis $D$. The other risk factors are; advanged age, chronic liver and renal disease, low fatty meal. Living in the RC and having mental disorders seemed as risk factors. Several researches support that hypovitaminosis $D$ is related to increase the risk of hip fracture (5-6). In many developed countries hip fractures in elderly is a serious public health problem. The risk of falling increases with age, fall is due to multiple reasons, such as loss of balance, muscle weakness. With VD supplementation; muscle strength in the lower extremity can be improvement, neuromuscular functions can be recovering so that fractures associated with falling reduced and non vertebral fracture ratio decreased \%43 to \%19 (6) in elder people. In a study from Russia, serum VD and PTH were detected lower in men and women with hip fracture than control groups. \%67 of hip fracture, $\% 47$ of control groups in VD level was $<25 \mathrm{nmol} / \mathrm{L}$ $(p=0.006)$. Similar to our study elderly people who were at RC in France and Australia, half of them, VD deficiency has been detected. They reported that with VD and calcium supplementation the frequency of fractures reduced (7).

CONCLUSION: Our study VD deficiency was detected in control groups who were not staying RC. This showed that they did not have enough physical activity and did not take enough dietary VD. In a study of healthy elderly in Japan Serum Vitamin D levels were detected seasonal changes (in winter $59.9 \mathrm{nmol} / \mathrm{L}$, in spring $65.1 \mathrm{nmol} / \mathrm{L}$, in summer 78.8 $\mathrm{nmol} / \mathrm{L})$ (52). More active people are known to be in contact with sunlight. In Nashimoto and et al. study seasonal differences were not found in elderly people in nursing house (8).

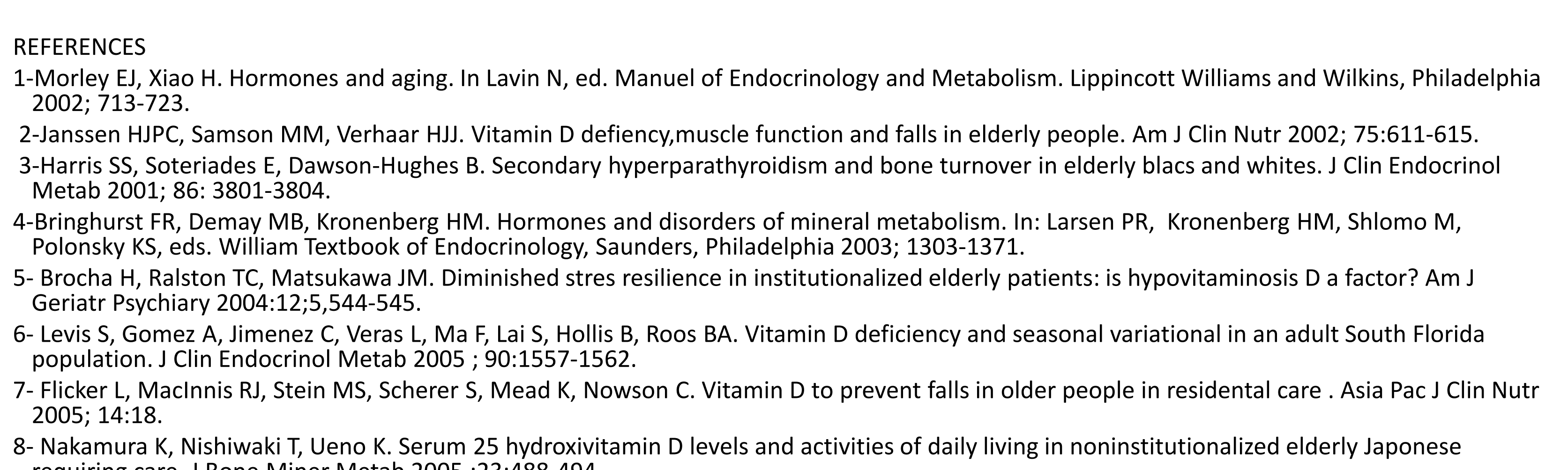

